\title{
HIV, harm reduction and human rights
}

$\mathrm{O}$ ne of the most important facts about the global AIDS epidemic facing us in 2005 is that $10 \%$ of new HIV infections are now related to illicit injection drug use. Outside Africa, at least one in three new infections results from the sharing of a contaminated needle. Russia, China, Malaysia, Ukraine and Vietnam have entrenched epidemics in which most cases are related to injection drug use. Injection drug use accounts for most cases in Tajikistan, Kazakhstan, Uzbekistan, Iran, Indonesia and Nepal and is the leading mode of transmission in most of Western and Eastern Europe, North Africa, and the Middle East. ${ }^{1}$

The fact that there are an estimated 13 million injection drug users (IDUs) in the world makes this state of affairs all the more urgent. As the authors of a report to the UN Millennium Project note, "injection-driven epidemics are ... distinguished by the extreme rapidity of their spread." The soaring infection rates among IDUs are in large measure the byproduct of a law-enforcement approach to drug policy, which deepens the social isolation of IDUs and presents barriers to harm-reduction strategies such as needle exchange and opioid substitution therapy. In some contexts, the paradoxical effects of the "war on drugs" are even more complex: "Law enforcement efforts restricting opium supplies lead users to shift to heroin use, or from smoking to injection. Criminalization of needle possession encourages use of shooting galleries or contaminated injection equipment." In many jurisdictions, the prisons and "treatment centres" where IDUs are incarcerated are themselves sites of drug trafficking, needle sharing and unprotected sex where harm-reduction measures are denied on the grounds that they condone criminal behaviour.

Another layer to this miserable picture is the generally poor access to antiretroviral (ARV) therapies among IDUs, even in developed countries. The WHO's " 3 by 5" initiative to deliver ARV therapy to 3 million people by the end of 2005 has brought the number of recipients from 440000 to 700000 , but this number accounts for only $12 \%$ of those who need it. Although the WHO has stipulated that ARV therapy should be made available to all, some jurisdictions report that none of the recipients of ARV therapy are IDUs. ${ }^{2}$ (A notable exception is Brazil, where a comprehen- sive harm-reduction and drug-access program reduced AIDS mortality among IDUs by $50 \%$.)

As Richard Elliott and colleagues discuss in this issue (see page 655), ${ }^{3}$ a harm-reduction approach to HIV control among IDUs is at odds with the prevailing framework of international drug control, which rests on law enforcement and the criminalization of behaviours related to illicit drug use. Treatment and rehabilitation are given lip service within the UN Drug Conventions, but the liberalization of drug policy and attempts to replace (or at least supplement) failed law enforcement policies with harm-reduction strategies have proceeded at a snail's pace.

Elliott and colleagues argue for a small but significant policy change as a matter of both pragmatism and human rights: namely, to promote access of IDUs to medical care by adding opioid substitutes to the WHO's Model List of Essential Medicines. In 1977 the WHO published its first such list: 208 therapeutic agents deemed to be the most efficacious, cost-effective and safe treatments available against the majority of infectious and chronic diseases, a pharmacologic tool kit needed by any health system that hopes to serve its population's basic health care needs and rights. From March 7-11 the UN Committee on the Selection and Use of Essential Medicines will consider applications for changes to the list; among those proposed are the addition of the opioid substitutes methadone and buprenorphine. We hope that including opioid substitutes to the WHOendorsed pharmacopeia will give timely support to the establishment and wider use of addiction treatment programs, and in so doing will help more IDUs to come inside the tent of HIV treatment and prevention. - CMAf

\section{References}

1. Wolfe D, Malinowska-Sempruch K. Illicit drug policies and the global HIV epidemic: effects of UN and national government approaches. Working paper commissioned by the HIV/AIDS Task Force of the Millennium Project. New York: Open Society Institute; 2004. Available: http://www.soros.org/initiatives /ihrd/articles_publications/publications/cnd_20040316 (accessed 6 Feb 2005).

2. Oppenheimer E, Hernandez Aceijas C, Stimson G. Treatment and care for drug users living with HIV/AIDS. London: Imperial College Centre for Research on Drugs and Health Behaviour; 2003. Available: www.ahrn.net/library upload/uploadfile/Treatment care for_DUs.pdf (accessed 6 Feb 2005).

3. Elliott R, Csete J, Palepu A, Kerr T. Reason and rights in global drug control policy [editorial]. CMA7 2005;172(5):655-6. 